\title{
Um clínico da atividade desejante no campo social: Félix Guattari
}

A clinician of the social desiring activity: Félix Guattari

Un clínico de la actividad deseante y social: Félix Guattari

\author{
Jésio Zamboni \\ Universidade Federal do Espírito Santo, Vila Velha, ES, Brasil. \\ Maria Elizabeth Barros de Barros \\ Universidade Federal do Espírito Santo, Vila Velha, ES, Brasil.
}

\begin{abstract}
Resumo
Discute-se, por vários argumentos, o desenvolvimento crítico da psicanálise pela atividade de Félix Guattari. O engajamento em lutas políticas diversas por um atravessamento diferenciante funciona como fonte dos desenvolvimentos da clínica. O encontro com o filósofo Gilles Deleuze marca uma posição de borda no meio psicanalítico, afirmando disjunções em psicanálise pelo princípio de transversalidade. A análise de R. A. por Guattari nos permite acompanhar essas experimentações por uma situação concreta de intervenção.
\end{abstract}

Palavras-chave: Félix Guattari (1930-1992), Clínica, Psicanálise, Transversalidade, Atividade.

\begin{abstract}
It is discussed by several arguments the critical development of the psychoanalysis by the work of Félix Guattari. The political engaging in several social struggles by differentiating crossings works as a source of developments of the clinical activity. The meeting with the philosopher Gilles Deleuze marks a position in the edge of the psychoanalysis operating disjunctions by the principle of transversality. The analysis of R. A. by Guattari allows us to track these experiments by a concrete situation of intervention.
\end{abstract}

Keywords: Félix Guattari (1930-1992), Clinic, Psychoanalysis, Transversality, Activity.

\section{Resumen}

Se discute por varios argumentos críticos el desarrollo del psicoanálisis en la obra de Félix Guattari. La participación en varias luchas sociales, mediante pasajes desestabilizantes, funciona como una fuente para la evolución de la actividad clínica. El encuentro con el filósofo Gilles Deleuze marca una posición en el borde del psicoanálisis por operaciones de 
disyunción a partir del principio de transversalidad. El análisis de R. A. por Guattari nos permite acompañar estos experimentos por una situación concreta de intervención.

Palabras clave: Félix Guattari (1930-1992), Clínica, Psicoanálisis, Transversalidad, Actividad.

\section{A atividade militante: integração dos diversos meios produtivos pela dimensão política}

Pierre-Félix Guattari (1930-1992) foi um psicanalista francês que emerge como trabalhador social no cenário do pós Segunda Guerra Mundial. É interessante notar que ele desenvolve diversos debates de modo a situar-se nos limites de sua atividade profissional. Nisso, pode-se já não saber mais exatamente se Félix é psicanalista ou não, se sua prática corresponde ao gênero profissional que a psicanálise estabelece, ou não. Ou melhor, os limites que ele insiste em habitar, por diversos modos, relativos ao seu estatuto profissional têm por função instaurar uma zona de produção de sentido e de variação estilística para a atividade analítica do desejo, implicando pragmáticas diversas no campo social. Eis o problema que nos propomos aqui a desenvolver: a clínica da atividade psicanalítica de Félix Guattari.

Guattari se colocou durante a vida em diversas situações de atividade militante político, administrador de estabelecimento de saúde mental, ativista cultural, editor de publicações impressas, coordenador de grupos de trabalho institucionais, etc. - que se cruzavam de modo tão intenso a ponto de constituir uma rede complexa e heterogenética capaz de possibilitar singularizações e criações diversas no campo social. Antes de abordar especificamente a atividade psicanalítica por nosso personagem, vejamos como se configuram as relações entre atividade e política, subjetividade e transformação social, em meio às atividades junto aos grupos militantes em que Guattari compôs; e, assim, pode-se sacar algumas perspectivas de como ele entra no meio psicanalítico, uma vez que psicanálise e militância se conjugam em Guattari.

Propomos fazer esse trecho já que o trabalho de psicanalista surge como possibilidade para Guattari num plano que decorre da sua atividade junto a grupos políticos articulados. Ele fora convidado por Jean Oury, psiquiatra e irmão mais velho de seu antigo professor na adolescência, Fernand Oury, ligado ao movimento de pedagogia institucional, para trabalhar numa clínica de "doentes mentais", a Clínica La Borde, a qual poderse-ia traduzir como "A Borda", "A Fronteira". Portanto, sua inserção nos 
meios de trabalho de saúde mental decorre de sua atividade política e dela não se separará, uma vez que esse cruzamento configura um ponto de emergência da construção do trabalho de Félix Guattari como psicanalista.

Jean Oury pedira que me reunisse à sua equipe - e, com isso, que interrompesse meus estudos de filosofia - pois precisava, pensava ele, de minha ajuda para desenvolver o Comitê intra-hospitalar da Clínica, em particular o Clube dos pensionistas. Minha suposta competência nesse domínio vinha do fato de que, desde os dezesseis anos, eu não cessara de “militar" em organizações tais como "os Albergues da Juventude" e toda uma gama de movimentos de extrema-esquerda. É verdade que eu sabia animar uma reunião, estruturar um debate, solicitar que as pessoas silenciosas tomassem a palavra, fazer surgir decisões práticas, retornar às tarefas anteriormente decididas... Em alguns meses, contribuí assim para a instalação de múltiplas instâncias coletivas: assembleias gerais, secretariado, comissões paritárias pensionistas-pessoal, subcomissão de animação para o dia, escritório de coordenação dos encargos individuais e "ateliês" de todos os tipos: jornal, desenho, costura, galinheiro, jardim etc. (Guattari, 1992, pp. 184-185)

A atividade de Guattari na clínica não se desenvolve numa restrição e no estabelecimento de um limite excludente com sua atividade militante. Pelo contrário, é no entrecruzamento dessas duas atividades que Guattari consegue desenvolver seu trabalho no meio clínico e no meio militante. Por essa intercessão, consegue sustentar a potência instituinte de rearranjar constantemente a organização do trabalho em função das necessidades concretas advindas da atividade cotidiana, onde os problemas políticos tomam chão pela experiência do labor, pela atividade produtiva. Tal perspectiva do trabalho de Guattari concorda com as considerações de Clot (1999/2006), para quem a criação no trabalho só é possível pela intercessão entre os diversos gêneros de atividade em que se situa o sujeito. Pelos deslocamentos entre os gêneros diversos, é possível criar novos modos de trabalhar e afirmar $\mathrm{o}$ movimento de constituição do sujeito num sentido que conjure os destinos definidos e os fatalismos daí decorrentes. A atividade militante será para Guattari privilegiada como intercessora à sua atividade clínica.

$$
\text { Guattari integrou formações }
$$

políticas buscando corporificar questões que os grupos de esquerda articulados se faziam incapazes de suportar em seus pontos críticos. Esses engajamentos políticos se faziam sobretudo por procedimentos de criação de linhas de fuga - experimentação que possibilita forjar o conceito mais tarde elaborado junto com Gilles Deleuze (Deleuze \& Guattari, 1980/2004). Guattari, em cada conjunto 
político em que se situa, tende a evocar e sustentar os impasses e limites pelos quais os grupelhos se definem, perturbando os fechamentos aos incômodos tensionamentos a que o campo social e desejante lhes convocam. A impossibilidade de programas e objetivos revolucionários últimos, acertados, racionais e monolíticos vai sendo conjurada pela postura de Guattari.

Desse modo, o militante afirma sua movimentação entre os bandos políticos como linha de fuga que o faz derivar sucessivamente do Partido Comunista Francês ao trotskismo, até a Via Comunista - "uma organização que surge nas fronteiras do trotskismo" (Dosse, 2007/2011, p. 37) -, aos movimentos estudantis e institucionais, aos movimentos de maio de 1968 na França e aos grupos políticos decorrentes desse movimento, às lutas ecológicas, dentre outras. "Quando Félix Guattari sente que uma instituição está se perpetuando, no vazio, na simples gestão de seu pequeno capital cultural, ele não hesita em tomar a dianteira e encerrar suas atividades, para abrir outras possibilidades fora dali." (Dosse, 2007/2011, p. 39). Guattari cria, então, linhas de fuga em meios aos bandos que permeia e atravessa; convida a uma ética que não feche a produção social, convocativa à criação e aos questionamentos incessantes, aos grupelhos detentores de um capital revolucionário em si mesmos.

Poderiam ser mencionados ainda outros engajamentos de Guattari que tendem cada vez mais a transversalizar as questões políticas articuladas a movimentos sociais diversos, tais como as rádios livres, os movimentos em rede de alternativa à psiquiatria, dentre outros. E acompanhar a passagem por esses coletivos vários, atentando-se aos cruzamentos com outras dimensões vitais, possibilitar-nos-ia acompanhar os processos produtivos que Guattari engaja, desde uma perspectiva que foca a dimensão do desenvolvimento de suas atividades, de seus processos criativos nos meios sociais. Pode-se perceber assim o quanto já se trabalha para confundir política e atividade, militância e produção. Não se sabe muito bem diferir os engajamentos políticos e as preocupações relativas aos modos de existência, de produção de relações, em meios de atividade situados, pela vida de Guattari.

Em meios militantes que se fecham sobre si, os sujeitos tendem a transcendentalizar os objetivos organizacionais e a si próprios, mesmificados como esclarecidos e esclarecedores da razão revolucionária. Diante da obstrução às conflitivas, que constituem a fonte dos movimentos sociais em suas diversas articulações, resta para 
Guattari fugir. Trata-se de fuga na luta, e não de fuga da luta. A fuga então tende a se distanciar da defesa coletiva que determinaria aos sujeitos uma redobra num si mesmo, uma identificação profissional militante. Esta defesa lança os paradoxos da atividade política à configuração de contradições insolúveis diante das quais resta optar por um lado - a verdade, o bem, a razão, o proletariado, o oprimido, etc. - e demonizar o outro, reificando as divisões, tornando-as naturais, numa prática militante reativa, distanciada da crítica. Em vez de reagir e rebater como continuação dos estados de coisas nos grupelhos, Guattari procura abrir outros campos de possibilidades, instituir meios de atividades diferenciantes pelas descontinuidades investidas como desapego a idealizações utópicas tendentes ao cessar das lutas num transcendente paraíso de liberdade absoluta.

Guattari (1972/2004) ao atacar a figura do revolucionário profissional, configurado no contexto do governo soviético stalinista, afirma paradoxalmente a figura do profissional revolucionário. A inversão dos termos pretende afirmar os paradoxos dessa luta, que não cessa num novo modelo a seguir, mas exatamente indica que é preciso não fixar os lugares da ação política nem da atividade produtiva. Trata-se de promover os atravessamentos das mais diversas atividades na vida pela dimensão política. É uma integridade política e existencial, laboral e vital, que Guattari sustenta paradoxalmente pela descontinuidade e dissociação com meios estabelecidos de ação.

$\mathrm{O}$ analista militante se desenha em Guattari não por duas áreas distintas de uma vida segmentada, mas por um atravessamento inextrincável entre política e produção, criação e pensamento, trabalho e luta. A análise para ele se processa pela própria atividade produtiva que não pode ser dissociada da política, do jogo de forças no plano coletivo. Guattari aponta como os complexos psicológicos são exatamente complexos sociais, acontecimentos no corpo coletivo (Guattari, 1977/1981; 1979/1988; 1972/2004; Guattari \& Rolnik, 1986/2008; Deleuze \& Guattari, 1980/2004; 19721973/2010). Portanto, não é possível acompanhar a atividade analítica de Guattari sem considerar a dimensão política, os agenciamentos no campo social pelos quais se faz, as maquinas de intervenção coletiva em que se forja.

\section{Encontro com Gilles Deleuze: intercessão para uma crítica à psicanálise}

$\mathrm{Se}$ os engajamentos políticos constituirão a existência de Guattari pelas atividades militantes diversas, sua 
atividade de analista do desejo será atravessada por essa existência e instalarse-á como linha de produção de subjetividade. As referências à psicanálise por parte de Guattari não cessarão desde as primeiras até as suas últimas obras escritas. Contudo, a cada vez sua posição no bando dos psicanalistas muda em função das situações em questão. A postura de Félix entre os psicanalistas a cada vez mais se configura como ponto de tensionamento, elemento de problematização das práticas, prosseguindo como desarranjo institucional, estilização da atividade psicanalítica e afinal como desterritorialização da análise da subjetividade, fuga no campo psicanalítico.

Em "Psicanálise

e Transversalidade" (Guattari, 1972/2004), reunindo textos de 1955 a 1971, trata-se sobretudo de tensionar o campo da análise do desejo, do inconsciente, do psiquismo, tal qual a psicanálise se demarcou, invadindo-o com questões relativas ao trabalho institucional e aos grupos militantes. Essa função de bárbaro revolucionário no meio psicanalítico confunde-se, intercambia-se, com a figura do trabalhador social, institucional. $\mathrm{O}$ ofício numa clínica psiquiátrica funciona como eixo problemático que se cruza com a série de paradoxos que se constitui pela atividade militante; não é possível separar um e outro. Como afirma Gilles Deleuze (1972/2006c, p. 249), “Acontece de um militante político e um psicanalista encontrarem-se na mesma pessoa e, em lugar de permanecerem isolados, eles não parem de se misturar, de interferir, de comunicar, de se tomar um pelo outro.”.

Até então, Deleuze também desenvolvia um trabalho de tensionamento da psicanálise; mas seu procedimento se distinguia do de Guattari por se instalar em oficina de produção conceitual, no campo da filosofia. Um nômade em posto de trabalho, operário dos conceitos é Deleuze: outras barbáries, outras militâncias, outras atividades. Quando se encontram em meio aos eventos de maio de 1968 na França, marcado por diversos movimentos sociais que formam uma rede de contestação dispersiva em convulsões múltiplas pelo corpo social, os bandos de Deleuze cruzam com os de Guattari. Esse atravessamento mútuo possibilitará a ambos uma crítica desde seus próprios limites nos usos dos instrumentos conceituais e funcionais psicanalíticos.

Não é que seus grupos de trabalho, famílias, amigos, interlocutores, se cruzem necessariamente; pelo contrário, eles se arranjam em pontos de intercessão pelas distâncias que se traçam entre um e outro num trabalho a dois. Essa intercessão não se dá por semelhanças, igualdades pretensas, ou por misturas indiferenciantes. Seu encontro opera pela conjuração de 
uma aliança por fusão, pela criação diferenciante que se sustenta nas controvérsias entre ambos. Os bandos que se atravessam pelo encontro e trabalho conjunto instauram uma política da amizade efetuando-se pela criação compartilhada, em que não se sabe mais muito bem quem está dizendo o que, na produção de agenciamentos coletivos de enunciação, que tratam as singularidades dos enunciados como produção coletiva, desejante e social. A partir do encontro dos amigos e do trabalho conjunto, suas relações de bando se modificam de modo bastante divergente do desenvolvimento em que se perfaziam, a ponto de se disporem rupturas.

Deleuze investe a criação conceitual, atacando a história da filosofia por seu próprio desenvolvimento, paradoxalmente. A partir de maio de 1968, intensifica uma conversa direta com os grupos militantes e institucionais por meio de Guattari. As relações deste professor de filosofia com a psicanálise se deslocam consideravelmente. Até então, ele investira diálogos conceituais com a psicanálise no sentido de desenvolvê-la pelos rumos em que se traçavam na França com Jacques Lacan, chegando mesmo a obrar "um ensaio de romance lógico e psicanalítico”, "Lógica do Sentido" (1969/2007, p. XVI). Tal relação com a psicanálise se sustenta, ainda que conteste perspectivas dominantes no meio psicanalítico, como o fez em sua análise de "Sacher Masoch: o frio e o cruel" (1967/2009). Deleuze desmonta o conceito de sadomasoquismo e trata do seu equívoco na (des)consideração da problemática de Masoch ao (con)fundila, ou seja, tratá-la como um complemento oposto, uma imagem de espelho invertida, à problemática política e desejante diversa do Marques de Sade. Desse modo, Deleuze contesta certas perspectivas em psicanálise, mas no sentido de fortalecê-la.

Pouco antes do encontro com Guattari, Deleuze (1968/2006a) publica sua tese de doutorado, "Diferença e Repetição", em que constrói uma obra que trata de problemas próprios, em vez de prender-se à leitura do trabalho de outros autores, possibilitando uma conversa mais ampla entre esses pelas questões que o atravessam como operário dos conceitos. Entretanto, a partir do encontro com Guattari, constrói-se um encontro interpessoal visando a um trabalho impessoal, uma vez que intenta construir um trabalho comum, e transpessoal, por envolver gêneros de atividades os mais diversos, bandos de atividades variadas. $\mathrm{O}$ trabalho próprio de Deleuze e Guattari se verá construído pela crítica ao indivíduo, que se pensa isoladamente das questões do mundo, questões políticas e sociais. Esse trabalho conjunto visa, sobretudo, constituir em obra filosófica, em 
ferramentas conceituais, os efeitos dos acontecimentos de maio de 1968 na França, as perturbações no pensamento que os acontecimentos sociais lhes provocaram.

\section{$O$ anti-édipo: posição de borda em psicanálise de Guattari}

Nesse encontro, transtornam-se as posições de ambos em relação à psicanálise como um campo de produção de saber e intervenção no campo social. Se até então Guattari e Deleuze produziam questionamentos pelos próprios meios psicanalíticos, "O anti-édipo" (Deleuze \& Guattari, 1972-1973/2010) situará suas contestações à análise psíquica numa posição limite. Será um trabalho incontornável, diante do qual a teoria e a prática psicanalíticas se verão confrontadas inelutavelmente. Diante desta obra, Lacan solicita aos que lhe seguem silêncio, num claro impedimento ao desenvolvimento das controvérsias implicando as práticas psicanalíticas emergentes na França, que se contentavam em criticar a psicologia do ego vigente nos Estados Unidos da América. Tratava-se, sobretudo de perpassar o dispositivo psicanalítico pelas questões do campo social, conjurando-lhe as transcendências e fechamentos às forças sociais em luta.
Deleuze e Guattari não se contentam apenas com os questionamentos no meio psicanalítico. Ao situar esse meio profissional no campo social, sua problematização se faz pelas práticas de análise desejante. Em desprendimento ao meio profissional fechado sobre si mesmo, propõem a esquizoanálise como análise desejante que "teria por ponto de aplicação ideal os grupos, e grupos militantes: pois é aí que se dispõe mais imediatamente de um material extra-familiar, e que aparece o exercício por vezes contraditório dos investimentos." (Deleuze, 1990/1992, p. 30).

A partir dessa proposta interrogamo-nos. Esses grupos não se compõem, por vezes, como coletivos de trabalho, já que não entendemos a militância como uma forma ou um modelo, mas como processo que se vive no plano das multiplicidades de forças no campo social? Não há nos coletivos de trabalho a disposição mais imediata desse material extrafamiliar nas diversas relações que se criam nos meios de trabalho? Não são nos coletivos de trabalho que as contradições de investimentos de produção social se apresentam de modo fulgurante, colocando-se em questão a criação de novos modos de luta social, uma vez que os tradicionais, como as greves e sindicatos, parecem mais do que nunca previsíveis e capturáveis? 
Pelo encontro com Deleuze, a posição de borda de Guattari com a psicanálise se fará à maneira de linha vibratória insuportável para muitos psicanalistas. A proposta esquizoanalítica firma-se como via para investimentos diversos em dispositivos múltiplos de intervenção e produção de subjetividade. Procura-se assim a quebra do cartel psicanalítico capitalizando as questões de subjetividade do campo social para os consultórios privados. Se "O anti-édipo" não é a ruptura absoluta com a psicanálise, no sentido de não cair num abandono como entrega dos pontos e desistência dos conflitos, se configura como conversa povoada de controvérsias abalando as bases do psicanalismo desde dentro.

Robert Castel (1973/1978) define o psicanalismo como a estratégia, no campo social, de obstrução dos atravessamentos da psicanálise pelas mais diversas questões políticas e desejantes, sociais e institucionais. Segundo ele, em "O antiédipo”, “a 'esquizo-análise' corresponde à vontade de fazer explodir a relação analítica do interior. Mas a difusão institucional da psicanálise pede seu próprio tipo de crítica prática." (Castel, 1973/1978, p. 236). É nesse sentido, de configuração de uma trincheira situada como crítica nos entremeios do plano social, como crítica institucional, que Castel desenvolve, quase paralelamente à
Deleuze e Guattari, sua própria crítica à psicanálise desde outras perspectivas institucionais. Constitui-se assim a crítica à psicanálise como meio povoado de controvérsias, permitindo aos seus desenvolvimentos não se instalarem como verdades absolutas descobertas desde um erro. $O$ anti-édipo é publicado no começo de 1972 e é sucedido pelo "O psicanalismo" de Castel, publicado em 1973. A comunicação entre os dois trabalhos se marca em um desses próprios trabalhos: nas últimas páginas de "O psicanalismo", Castel dialoga com "O antiédipo", como anotamos aqui.

\section{Disjunções em psicanálise: efeitos d'O anti-édipo}

A partir de "O anti-édipo", as relações com a psicanálise tendem cada vez mais a passar de críticas estremecentes perturbadoras a uma linha de fuga em potência transversalizante elevando-se velozmente. Havia, a princípio, críticas pontuais a certas colocações complicadas em psicanálise, seja pelo problema do sadomasoquismo abordado por Deleuze (1967/2009), seja pela questão da abordagem institucional desenvolvida por Guattari (1972/2004) em conflitos dialógicos pontuais com o lacanismo a pleno vapor. Guattari produzia modos problematizantes de trabalho em 
psicanálise, estilizações do ofício de analista do desejo, posições limites diante da instauração de um novo regime psicanalítico desde Lacan que se colocava como retorno às fontes freudianas deturpadas, o que implicava a negligencia e complicação da abordagem institucional. Entretanto, Guattari procura sustentar o debate polifônico e controverso no seio da Escola Freudiana de Paris. Em meio a esses debates formigando em vários pontos de discussão, tanto Deleuze como Guattari, à beira de seu encontro, afirmam ainda intensamente suas relações com a psicanálise.

Mas tal aproximação se configura mais tarde como cumprimento entre lutadores que logo a seguir se digladiarão em séries de disputas bastante terríveis. Guattari, em disposição amigável a essa batalha avistando-se, escreve para Lacan "Máquina e estrutura", texto publicado em "Psicanálise e Transversalidade" (1972/2004). Mas essa saudação será o disparo incômodo que, de um tiro só, o aliará a Deleuze e instaurará um conflito com Lacan e seus seguidores, que não suportarão bem a estilização da psicanálise pelo trabalho de Guattari. Lacan irá atrapalhar a publicação do texto de Guattari e a seguir "ordena aos membros da Escola Freudiana [de Paris] que mantenham total silêncio, que não comentem nem participem de nenhum debate [acerca de "O anti-édipo"]." (Dosse, 2007/2010, p. 177). Entretanto, não cabe delimitar a disputa ao campo psicanalítico, uma vez que seria negligenciar os efeitos de maio de 1968 nesses conflitos. São as questões que percorrem o corpo social que o provocam, promovem e sustentam.

Guattari e Deleuze insistem nesses diálogos com a psicanálise, mas desde outra postura a partir de "O anti-édipo". Tal obra é essa insistência, movimento de provocação, em dispor as variantes do trabalho analítico relativo à subjetividade como estilizações da psicanálise em termos de instrumentos conceituais. Tais variações dependiam, como se vê pelo "O antiédipo" de cabo à rabo, de intercessões com outros terrenos de práticas e saberes: literatura, história, etnologia, economia, filosofia, dentre outras. Mas essas intercessões não se podiam fazer por uma permanência daquilo que o campo psicanalítico poderia cercar como saber exclusivo: o domínio da subjetividade. Seria preciso encarar, num plano imanente de diálogo que situasse a psicanálise dentre outras atividades sem limites cabalmente determinados, os conflitos decorrentes dessas conversações e as variações internas à psicanálise provocadas nesses limites. Contudo, a atitude de Lacan é compartilhada por muitos analistas desde então e o psicanalismo tende a barrar as 
conflitivas cruciais ao desenvolvimento da psicanálise.

Mas insiste-se. "Deleuze e Guattari explicam-se" (Deleuze, 1972/2006b) numa mesa redonda em 1972 junto a diversos interlocutores que se colocam como profissionais dos gêneros diversos de atividades que são convocadas para conversas em "O anti-édipo". A conversação acentua-se especialmente na conflitiva com a psicanálise, destacada pelo diálogo com Serge Leclaire, psicanalista. A partir dessa conversa, já se apresenta um tensionamento bastante difícil de encaminhar nos quadros da psicanálise. Acompanhemos alguns traços relativos a esse debate. Leclaire afirma:

Creio que a vossa máquina desejante, que só deveria funcionar ao desarranjar-se, ou seja, com as suas avarias, com as suas falhas de motor, é tornada completamente inofensiva por vocês próprios, em virtude do objeto "positivado", da ausência de toda dualidade e de toda a "falta", vai trabalhar como... um relógio suíço. (Leclaire, citado por Deleuze, 1972/2006b, p. 284).

Tal crítica nos conduz às oposições remetidas às máquinas de abordagem da atividade nos mundos do trabalho. Insistentemente interrogadas por colocarem-se em favor da produtividade, da qualidade do trabalho, tais perspectivas de intervenção nos mundos do trabalho são denunciadas por não conduzirem à revolução nos meios de produção. Ainda que se proponha a desarranjar a organização do trabalho, no que ela sufoca os processos produtivos, pelas variações criativas e pela subversão dos sentidos da atividade, solicita-se a esses aparelhos uma negativa declarada. Entretanto, trata-se de afirmar as positividades das lutas por meio dos paradoxos no trabalho em vez de debater-se em contradições pela negativa da situação laboral. Tal posição é comum à assumida por Deleuze e Guattari no campo psicanalítico.

No debate com Leclaire, já se avistam, contudo, distintas posições de Guattari e Deleuze relativas ao debate com os psicanalistas. Deleuze radicalmente rompe a ligação que alimentara até então com a psicanálise e dispõe-se a críticas visando ao desmonte da máquina psicanalítica e seus aparelhos. Guattari, por sua vez, insistirá no debate com a psicanálise, o que marcará seus trabalhos posteriores, mas desde a posição construída no trabalho conjunto com Deleuze. O meio comum em que se desenvolvem e podem prosseguir em conversações essas diferentes posturas é a esquizoanálise.

Durante os anos seguintes, Guattari não abandona seus meios de atividade. As perturbações e fugas que se empreenderam por seu trabalho psicanalítico visaram 
desenvolvê-lo, sem temer as rupturas, mas sustentando as controvérsias próprias ao meio. A esquizoanálise se faz em Guattari, como em Deleuze, pela perturbação de seus meios próprios de trabalho. Guattari faz esquizoanálise pelas práticas psicanalíticas, assim como Deleuze pelas práticas filosóficas. Nesse sentido, a ruptura com a psicanálise é ruptura na psicanálise, pela psicanálise, possibilitando que as práticas analíticas não se fechem nos dispositivos estabelecidos. As máquinas de análise do desejo não têm proprietários e herdeiros desde a sua constituição, mas nem por isso implicam que a máquina não funcione e não produza de tal maneira que possa ser expropriada para outros usos, afirmando a invenção nela própria.

\section{Transversalidade analítica ou adeus à psicanálise?}

Guattari irá desenvolver na década de 1970, sempre em diálogo com Deleuze, direta ou indiretamente, toda a potência disruptiva relativa ao seu trabalho conjunto com o amigo filósofo em "O anti-édipo". São exploradas as consequências da proposição da esquizoanálise nesses anos seguintes ao ponto crucial de logo no começo de "Mil platôs" (Deleuze \& Guattari, 1980/2004) se declarar a despedida à psicanálise. Propõe-se por este procedimento que o novo trabalho se liberasse do debate centrado no meio próprio à psicanálise, afirmando uma transversalidade radical da produção desejante e social nos diversos meios de atividade coletiva.

\footnotetext{
Em Mil platôs, o comentário sobre o homem dos lobos ("Um só ou vários lobos") constitui nosso adeus à psicanálise, e tenta mostrar como as multiplicidades ultrapassam a distinção entre a consciência e o inconsciente, entre a natureza e a história, o corpo e a alma. As multiplicidades são a própria realidade, e não supõem nenhuma unidade, não entram em nenhuma totalidade e tampouco remetem a um sujeito. As subjetivações, as totalizações, as unificações são, ao contrário, processos que se produzem e aparecem nas multiplicidades. (Deleuze e Guattari, 1980/1995, p. 8)
}

Em "Mil platôs" trata-se de expandir as questões levantadas em torno do marxismo e da psicanálise como concernentes a diversos saberes e práticas. Neste segundo tomo de "Capitalismo e esquizofrenia", portanto, a transversalidade dos saberes é destacada e novas questões se colocam desde terrenos já bastante distantes da psicanálise e do marxismo. Não se trata, entretanto, de renegar esses dois eixos problematizantes das nossas vidas contemporâneas, mas de não tomálos como sobrecodificações às quais outros 
saberes devam render homenagem, cuja importância se faz pelos usos possíveis nas análises produtivas.

Neste novo trabalho, trata-se de tomar a linha vibratória e flexível, perturbando os limites da psicanálise, como linha de fuga que perpassa diversos planos problemáticos. As conexões entre os diversos problemas não se colocam a priori, mas se fazem nas experiências de trabalho e vida de Guattari e Deleuze, nas questões que perpassam situações sociais diversas em que participam de algum modo, seja pela filosofia, pela clinica, pela docência, pela militância. A psicanálise, neste novo empreendimento, aparece tão fragmentada e esparsa que se pode cogitar sua completa negação. Mas o adeus anunciado é esquecimento que instaura as ferramentas analíticas da psicanálise no corpo apropriante que as transforma em função das situações contemporâneas, em vez de evocar-lhes sempre a lembrança em busca dum recalcado inatingível.

Quando Guattari vem ao Brasil em 1982, Suely Rolnik o acompanha e organiza um livro constituído principalmente pelas diversas conversas engajadas com os mais variados grupos, dentre os quais figuram diversos psicanalistas em suas organizações no país (Guattari \& Rolnik, 1986/2008). "Desejo e História”, um dos capítulos do livro, concentra os debates com os psicanalistas que, entretanto, se espalham por todo o livro. Aí, Félix tem oportunidade de estabelecer conversações em controvérsias acerca da psicanálise com outros colegas de ofício em terras estrangeiras e registrar isto numa obra, de tal modo que não se perca de vista seu ofício como trabalhador social em psicanálise. O diálogo se instala, dentre diversos assuntos, em torno de temas relativos à profissionalização da psicanálise - o que nos interessa ao propormos debater a atividade psicanalítica a partir de Guattari.

Diante da questão que lhe fazem durante uma dessas várias conversas de que a psicanálise ou a clínica de modo geral seriam lugares privilegiados do analítico, Guattari responde: "É claro que não. O que não é sinônimo de uma condenação do métier [ofício] de psicoterapeuta ou de qualquer função de trabalhador social. [grifo dos autores]" (Guattari \& Rolnik, 1986/2008, p. 244). Por essa perspectiva, Guattari promove análises da atividade psicanalítica referindo-se às práticas e aos processos de institucionalização implicados nessas práticas. Sendo assim, Guattari ataca o especialismo que pretende tornar exclusiva a atividade analítica pelo mesmo golpe em que afirma os coletivos próprios de trabalho contra a generalização.

Não retomaremos extensivamente aqui, contudo, as análises empreendidas 
por Guattari acerca da psicanálise uma vez que isso nos ocuparia uma enormidade de trabalho. Em vez disto, tomaremos a sua própria atividade como objeto de análise a partir principalmente dum caso clínico registrado por Guattari, em que assumiu a posição de psicanalista pela primeira vez. Ainda outras referências à sua atividade psicanalítica serão evocadas por nós para elucidar algumas questões relativas ao desenvolvimento da sua atividade. Procuramos com isso retomar a problemática da atividade, tal como Clot (1999/2006; 2008/2010) a define, ou seja, a atividade é todo o jogo de forças com suas tensões produzindo movimento pelo sujeito. Isto é para trazer à tona a dimensão crítica à psicanálise em Guattari. Com esse empreendimento, pretendemos antes destacar as estilizações na atividade psicanalítica promovidas por Guattari.

\section{R. A. e a constituição de um dispositivo analítico: máquinas desejantes e polifonia discursiva}

É preciso situar, antes de tudo e mais uma vez, que o contato de Guattari com a atividade psicanalítica é promovido por seu amigo e colega de trabalho na clínica La Borde, Jean Oury, e por Jacques Lacan, do qual conhece os textos por Oury e de quem acaba por se aproximar frequentando seus seminários e seu divã
(Dosse, 2007/2010). Oury era bastante influenciado pelo trabalho de François Tosquelles. Este promoveu a acolhida de militantes perseguidos e a liberação de “doentes mentais" para a vida comunitária diante dos acontecimentos da Segunda Grande Guerra Mundial a partir do Hospital Saint-Alban, desenvolvendo a seguir junto a diversos outros psiquiatras problematizações acerca da instituição psiquiátrica e das práticas de cuidado que se constituíram logo como psicoterapia institucional. Oury segue ainda o trabalho de Lacan, que lança diversos questionamentos às práticas hegemônicas da psicanálise na metade do século XX. A atividade psicanalítica de Guattari, disparada por Oury, será também crucialmente marcada por Tosquelles e Lacan, embora não se prenda a essas referências. $\mathrm{Na}$ clínica, Guattari é sobretudo um organizador preocupado com a dimensão institucional, com as normas, regras, valores, modos de funcionamento coletivo. Isto justamente por suas propostas de transversalização das atividades, de assumir por vezes o lugar de psicanalista como meio, passagem.

Guattari registra um dos casos clínicos que desenvolve junto com um dos pacientes de La Borde. Trata-se de um sujeito, chamado por Guattari de R. A., que não se integra "ao sistema da terapia ergosocial da clínica" (Guattari, 1972/2004, p. 
35), ou seja, à proposta de trabalhos conjuntos entre pacientes e cuidadores em oficinas. Tem-se aí um desafio às propostas de gestão desenvolvidas por Guattari. As experiências de atividades grupais possibilitam que R. A. abandone suas atitudes de afastamento e paralisação diante dos outros mas não que estas sejam necessariamente superadas, como aponta Guattari. Não se trata portanto, no trabalho grupal, de uma estratégia infalível de prática terapêutica mas de um dispositivo possível para o trabalho de cuidado (Barros, 1994/2007; César, 2008). É neste quadro desafiador aos processos de gestão que pela atividade cotidiana Guattari consegue estabelecer contatos e constituir dispositivos analíticos junto com R. A.

Tendo estado bem próximo a ele no decorrer de todas essas atividades, tendo tido a oportunidade de encontrá-lo no bosque e de acompanhá-lo de volta, quando de sua fuga, assim como por razões de simpatia, foi-me bem fácil fazer com que aceitasse a perspectiva de um diálogo. Foi importante evitar, desde o começo, que se instaurasse entre nós uma relação de tipo "transferencial". Primeiro porque umas poucas sessões de psicoterapia tinham sido interrompidas três anos antes, por razões, a propósito, externas, tendo-o deixado em tenebrosa sensação de fracasso, e em segundo lugar por causa da estrutura da clínica, que implica, para todo membro do corpo de funcionários, a necessidade de uma

\begin{abstract}
presença alternativamente "curativa" e "autoritária", "amigável" etc., de modo que a transferência psicanalítica teria vida curta, uma vez que, ao final da sessão o analista seria levado a ter para com o sujeito uma atitude completamente distinta. (Guattari, 1972/2004, p. 36)
\end{abstract}

Pode-se perceber pelo estabelecimento desta relação analítica como a clínica se faz como crítica à psicanálise, como posição de borda em relação aos procedimentos e instrumentos conceituais e técnicos dos quais se lança mão. Contrariando a hegemônica atitude de aplicação de uma ferramenta supostamente acabada, Guattari problematiza a psicanálise na instituição desde os imprevistos da situação de trabalho com os quais ele procura resolverse desenvolvendo variações instrumentais na atividade. Estas experimentações são desenvolvidas em análises situadas desde os problemas concretos que ele trata de acompanhar como clínico. É assim também potencializada a produção de ferramentas de análise em modulações dos dispositivos da clínica.

Guattari extrairá das experimentações em atividade situada, como esta com R. A., questões para o trabalho do psicanalista. Trata-se sobretudo de pistas, indícios e apontamentos que nem por isto deixam de se afirmar como estilizações no corpo genérico de 
profissionais psicanalistas. Em relação à transferência, fenômeno clínico em que se atualizam emoções, pensamentos e ações deslocados desde uma situação passada para o presente por conta da clínica, Guattari afirma que

sempre que ocorre a transferência, é que se instaurou uma situação de alienação, o que provavelmente funciona como obstáculo aos verdadeiros processos analíticos [itálicos dos autores]. Na época de minha carreira de analista tradicional, eu tinha estabelecido uma espécie de analogia entre todos os começos de análise; cheguei até a confirmar isso com outros analistas. A mim parecia que no começo dos tratamentos, da primeira sessão até o quinto, sexto, sétimo mês, mais ou menos, existia e se mantinha uma certa produtividade. No entanto, a partir daí acontecia uma espécie de fenômeno global de massificação, de solidificação, correspondendo à instauração de fenômenos de transferência, que funcionariam, durante anos a fio, como um verdadeiro fenômeno de implosão dos processos analíticos. (Guattari \& Rolink, 1986/2008, p. 315)

Promovendo controvérsias acerca da função da transferência na atividade psicanalítica, geralmente definida como o momento de estabelecimento da relação analítica, propiciado pelo dispositivo montado com a associação livre e o jogo da confissão entre analisante e analista,
Guattari assume uma posição radical ao definir a transferência como obstáculo, como buraco negro que atrapalha a produtividade da análise. Deixa-se de lado assim a ambivalência que Sigmund Freud propõe sustentar pela transferência e radicaliza-se na transmutação do dispositivo de análise.

Cabe pontuar que este desenvolvimento se processa em consideração da dimensão institucional da psicanálise situada em locais de trabalho. Em vez de se considerar que, com a transferência, a análise dispara, Guattari afirma que se trata de um breque, de um beco sem saída de retorno ao passado familiarista. As discussões de Deleuze (1986/2005) acerca da função produtiva do esquecimento vão também neste sentido. Não é à toa portanto que Guattari afirme que, com esses desenvolvimentos, já não se trata da carreira de analista tradicional.

Mas retomemos o caso de R. A., pois a análise situada é a fonte dos desenvolvimentos da clínica psicanalítica com Guattari. Evitando a transferência, Guattari instala um gravador de áudio durante as sessões com R.A.. Posteriormente, tratava-se de reproduzir os discursos do analisante, visando "uma espécie de objetivação da situação cujo efeito era na maioria das vezes [paradoxalmente] o de desviar, senão de bloquear, o diálogo.” (Guattari, 1972/2004, 
p. 37). Os impasses aos processos produtivos portanto não remetem, para Guattari, às memórias etéreas familiares, mas a situações de experimentação no real dos dispositivos de produção de subjetividade. $\mathrm{O}$ familiarismo e sua atualização pela transferência seriam buracos negros, zonas de relação da qual se obstruem as saídas, nas quais os paradoxos da atividade não teriam lugar para se desenvolverem.

Os impasses, bloqueios e desvios na clínica entre Guattari e R. A. são suscitados pela confrontação de R. A. com seu próprio discurso, provocando um desenvolvimento dialógico. Diante do que fala, R. A. estranha-se e pode-se colocar em controvérsia com "aquele tom monocórdico, aquelas hesitações, aquelas interrupções, as incessantes incoerências" (Guattari, 1972/2004, p. 37). A polifonia discursiva torna-se possível a partir da confrontação de perspectivas, por controvérsias, em si próprio. É essa polifonia que permite o contato com o real, o processo de produção em seus limites de ação e sentido. As "incessantes incoerências" podem se desenvolver afinal por singularizações em que cabe construir horizontes de possibilidades outras para a atividade, para além de sua estagnação.

Partindo do gravador de áudio e de sua disposição singular na situação analítica construída, inventam-se outros dispositivos de confrontação discursiva: a produção de um filme amador em que $\mathrm{R}$. A. participa como ator e espectador; a cópia do livro “O castelo”, de Franz Kafka, autor que teria grandes semelhanças com R. A., segundo Guattari; um caderno de anotação das falas, em substituição ao gravador, que se torna, posteriormente, um texto próprio de R. A., em que "Ele remanejou coisas, corrigiu, aprimorou, selecionou, fez comentários ao que havia ali, alterou a ordem daquilo que havíamos elaborado juntos." (Guattari, 1972/2004, p. 40). Cada um desses dispositivos, dessas pequenas máquinas de análise, Guattari discute em função dos movimentos de produção de subjetividade na clínica de R. A.. Cada um implica modos de uso, procedimentos que vão se inventando no curso da atividade clínica, diante da qual Guattari não teme uma série de inovações em função da situação que se produz e desloca.

Mas por que essa variação constante de dispositivos? Para Guattari, nos parece, é o caso de não tornar a análise fechada a um dispositivo hermético, a uma máquina exclusiva, tal qual acontece com a psicanálise, mas de suscitar a invenção de máquinas analíticas abertas à variação e à criação, de se inventar meios de análise próprios a cada situação. Nas confrontações dialógicas promovidas pelas máquinas inventadas entre Guattari e R. A. 
na clínica La Borde, trata-se a cada vez de invocar, o que Clot (2008/2010) define como, o sobredestinatário da confrontação, e que Deleuze (1991/2003) aponta como, a dimensão impessoal das conversações, ambos a partir de Mikhail Bakhtin.

O sobredestinatário do diálogo remete, portanto, à dimensão impessoal na conversação, que nunca pode então ser binarizada, remetendo sempre à polifonia discursiva, à multiplicidade de sentidos do discurso, que cabe percorrer inventando vias singulares. Guattari irá explorá-lo como máquina, o que se aponta pela sua “A paixão das máquinas” (Guattari, 2003), principalmente em seus trabalhos sob a insígnia de esquizoanálise. O conceito de máquina desejante desenvolverá a polifonia discursiva como agenciamento coletivo de enunciação desde as produção efetivas no campo social, tomadas como agenciamentos maquínicos do desejo. Guattari estabelece em condição de produto, de resto circulante entre as máquinas, o sujeito como adjacência à máquina. Isto se faz em função de uma perspectiva radical de alteridade, remetida não a pessoas globais desde o eu próprio, mas ao estranhamento desestabilizante, que pode disparar processos de produção de sujeitos e mundos. Em Guattari (1992), a polifonia bakhtineana sobrepõe-se à consideração dialógica no que ainda possa privilegiar a interlocução subjetiva por binarismos linguísticos ou retomadas da função egóica.

$$
\text { Guattari, pelas suas }
$$
experimentações clínicas, já na década de 1950, aborda as dimensões maquínicas e polifônicas, produtivas e expressivas, que orientarão sua produção conceitual nos anos posteriores. A atenção às máquinas desejantes inventadas entre Guattari e R. A., bem como à produção de enunciações coletivas entre ambos, marcará e orientará o trabalho analítico de Guattari nos anos seguintes. Portanto, mostra-se crucial, para acompanhar a invenção e uso dos conceitos e procedimentos em esquizoanálise, situar as experimentações analíticas que provocam seus desenvolvimentos.

\section{Referências}

Bakhtin, M. (1997). Os gêneros do discurso. In M. Bakhtin, Estética da criação verbal (2a ed., pp. 277-287). São Paulo: Martins Fontes. (Original publicado em 1952-1953).

Barros, R. D. B. (2007). Grupo: a afirmação de um simulacro. Porto Alegre: Sulina.

Castel, R. (1978). O psicanalismo. Rio de Janeiro: Graal. (Original publicado em 1973).

César, J. M. (2008). Processos grupais e o plano impessoal: a grupalidade fora 
no grupo. Dissertação de Mestrado. Programa de Pós-Graduação em Psicologia, Universidade Federal Fluminense, Niterói, RJ.

Clot, Y. (2006). A função psicológica do trabalho. Petrópolis, RJ: Vozes. (Original publicado em 1999).

Clot, Y. (2010). Trabalho e poder de agir. Belo Horizonte: Fabrefactum. (Original publicado em 2008).

Deleuze, G. (2009). Sacher-Masoch: o frio e o cruel. Rio de Janeiro: Jorge Zahar. (Original publicado em 1967).

Deleuze, G. (2006a). Diferença e repetição (2a ed.). Rio de Janeiro: Graal. (Original publicado em 1968).

Deleuze, G. (2007). Lógica do sentido (3a reimp. da $4 a$ ed.). São Paulo: Perspectiva. (Original publicado em 1969).

Deleuze, G. (2006b). Deleuze e Guattari explicam-se. In G. Deleuze, A ilha deserta: e outros textos: textos e entrevistas (1953-1974) (pp. 277292). São Paulo: Iluminuras. (Original publicado em 1972).

Deleuze, G. (2006c). Três problemas de grupo. In G. Deleuze, A ilha deserta: e outros textos: textos e entrevistas (1953-1974) (pp. 249-260). São Paulo: Iluminuras. (Original publicado em 1972).
Deleuze, G. (2005). Foucault. São Paulo: Brasiliense. (Original publicado em 1986).

Deleuze, G. (1992). Conversações: 19721990. São Paulo: Ed. 34. (Original publicado em 1990).

Deleuze, G. (2003). Préface : une nouvelle stylistique. In G. Deleuze, Deux régimes de fous: textes et entretiens (1975-1995) (pp. 343-347). Paris: Minuit. (Original publicado em 1991).

Deleuze, G., \& Guattari, F. (2010). $O$ antiédipo: capitalismo e esquizofrenia 1. São Paulo: Ed. 34. (Original publicado em 1972-1973).

Deleuze, G., \& Guattari, F. (1995). Mil platôs: capitalismo e esquizofrenia (Vol. 1). São Paulo: Ed. 34. (Original publicado em 1980).

Deleuze, G., \& Guattari, F. (2004). Mil mesetas: capitalismo y esquizofrenia (6ta ed.). Valência, Espanha: Pretextos. (Original publicado em 1980).

Dosse, F. (2010). Gilles Deleuze \& Félix Guattari: biografia cruzada. Porto Alegre: Artmed. (Original publicado em 2007).

Guattari, F. (2004). Psicanálise $e$ transversalidade: ensaios de análise institucional. Aparecida, SP: Idéias $\&$ Letras. (Original publicado em 1972). 
Guattari, F. (1981). Revolução molecular: pulsações políticas do desejo. São Paulo: Brasiliense. (Original publicado em 1977).

Guattari, F. (1988). $O$ inconsciente maquínico: ensaios de esquizoanálise. Campinas, SP: Papirus. (Original publicado em 1979).

Guattari, F., \& Rolnik, S. (2008). Micropolítica: cartografias do desejo (9a ed.). Petrópolis, RJ: Vozes. (Original publicado em 1986).

Guattari, F. (1992). Caosmose: um novo paradigma estético. São Paulo: Ed. 34.

Guattari, F. (2003). A paixão das máquinas. In $O$ reencantamento do concreto (pp. 39-52). São Paulo: Hucitec.

$\overline{\text { Jésio Zamboni é graduado em Psicologia }}$ (2008), mestre em Psicologia Institucional (2011), doutorando em Educação e Pesquisador do Núcleo de Estudos e Pesquisas em Subjetividade e Políticas (NEPESP) e do Grupo de Estudos em Sexualidades (GEPSs) pela Universidade Federal do Espírito Santo. Bolsista da Fundação de Amparo à Pesquisa do Espírito Santo (FAPES).

E-mail: jesiozamboni@gmail.com

\section{Maria Elizabeth Barros de Barros é} Professora Titular do Departamento de
Psicologia e dos Programas de PósGraduação em Psicologia Institucional (PPGPSI) e em Educação (PPGE) da Universidade Federal do Espírito Santo. Possui graduação em Psicologia pela Universidade Federal do Rio de Janeiro (1975), Mestrado em Psicologia Escolar pela Universidade Gama Filho (1980), Doutorado em Educação Brasileira pela Universidade Federal do Rio de Janeiro (1995) e Pós-Doutorado em Saúde Coletiva pela ENSP/Fiocruz (2001). Pesquisadora do Núcleo de Estudos e Pesquisas em Subjetividade e Políticas.

E-mail: betebarros@uol.com.br 